\title{
Cytological Studies on Seven Species of Korean Carex (Cyperaceae)
}

\author{
Kyong-Sook Chung ${ }^{1 *}$, Takuji Hoshino ${ }^{2}$, Tomomi Masaki², \\ Jong Cheol Yang ${ }^{3}$ and Hyoung-Tak $\mathrm{Im}^{4}$
}

\footnotetext{
${ }^{1}$ Department of Medicinal Plant Science, Jungwon University, Goesan-gun, Chungbuk 28024, Korea

${ }^{2}$ Department of Biosphere-Geosphere Science, Faculty of Biosphere-Geosphere Science, Okayama University of

Science, 1-1 Ridai-cho, Kita-ku, Okayama-shi, Okayama 700-0005, Japan

${ }^{3}$ Division of Forest Biodiversity, Korea National Arboretum, Pocheon-si, Gyeonggi-do 11186, Korea

${ }^{4}$ Department of division of Biological Science, Chonnam National University, Gwangju 61186, Korea
}

Received October 8, 2015; accepted March 20, 2016

\begin{abstract}
Summary Chromosome numbers of seven Carex taxa collected from the Korean peninsula are reported. This study is the first observations of meiotic chromosomes for Carex species from Korean populations. A univalent is observed in C. ischnostachya Steud. var. fastigiata T. Koyama $(n=26 \mathrm{II}+\mathrm{I})$, and two different chromosome numbers are observed in an individual of $C$. leucochlora Bunge ( $n=27 \mathrm{II}, 29 \mathrm{II})$. For the first time, the chromosome number for $C$. polyschoena H. Lév. \& Vaniot $(n=26 \mathrm{II})$ is reported here. The results of diverse chromosome numbers suggest that polyploidy and aneuploidy including agmatoploidy and symploidy (increases and decreases in chromosome number due to fission or fusion, respectively) have played an important role for Carex species diversity in Korea.
\end{abstract}

Key words Agmatoploidy, Carex, Chromosome, Cyperaceae, Korea.

Genus Carex (Cyperaceae) is the largest angiosperm genus in the temperate zone, comprised of more than 2000 species worldwide (Reznicek 1990, The Global Carex group 2015). The genus exhibits high variance in chromosome numbers ranging from $n=6$ to $n=66$ with every haploid number between $n=6$ and $n=48$ (Tanaka 1949, Davies 1956, Roalson 2008, Hipp et al. 2009). The cytogenetic variance is hypothesized to be due to the non-localized centromeres (holocentric chromosomes), which facilitate chromosome number increases (agmatoploidy) and/or decreases (symploidy) by fission and fusion, respectively (Hoshino 1981, Nishikawa et al. 1984, Luceño and Guerra 1996, Chung et al. 2011, Hipp et al. 2013). Cytological studies have been very informative on taxonomy and phylogeny of Carex (Rothrock et al. 2009, Yano et al. 2010) and high chromosome number variations have been hypothesized to play an important role on rapid speciation in the genus (Hipp 2007, Hipp et al. 2009, Hipp et al. 2010, Chung et al. 2012, Escudero et al. 2012).

About 157 taxa of Carex are distributed in Korea, with Cyperaceae one of the most important components in the Korean flora as the second largest family following Asteraceae (Oh 2007, Kim et al. 2008). Although chromosome number variations are well-known features in Carex speciation, only a few chromosome studies have been conducted on Korean Carex populations.

\footnotetext{
* Corresponding author, e-mail: kchung@jwu.ac.kr DOI: $10.1508 /$ cytologia.81.143
}

Kim (2006) and Lee and Kim (2008) reported somatic chromosome numbers of three species: C. blepharicarpa var. stenocarpa Ohwi $(2 n=20), C$. siderosticta Hance $(2 n=12)$, and $C$. okamotoi Ohwi $(2 n=12)$. Recently, somatic chromosome numbers of Carex sect. Siderostictae were counted from multiple populations of Korea. The study confirmed the chromosome evolution from large chromosomes (about 2-4 $\mu \mathrm{m}$ long) with small numbers $(2 n=12)$ to smaller chromosomes (less than $1 \mu \mathrm{m}$ long) with high numbers (Chung et al. 2013). The deficiency of cytological information on Korean Carex species has resulted in difficulty in understanding Korean species diversity and cytological character evolution in Carex as a whole.

In this paper, we report chromosome numbers of seven Carex species from Korean populations and discuss the significance of their taxonomic and cytological characteristics.

Materials and methods

The chromosome numbers of seven species in Carex from Korean populations were analyzed. To determine meiotic chromosomes, live plants were collected from natural populations and then cultivated at the Jungwon University (Province Chungchungbuk-do, Korea) and/or Korea National Arboretum (Province Gyeonggi-do, Korea). The methods for chromosome observation mainly followed Rothrock and Reznicek (1996), fixing immature spikes in a mixture of methanol, chloroform, and 

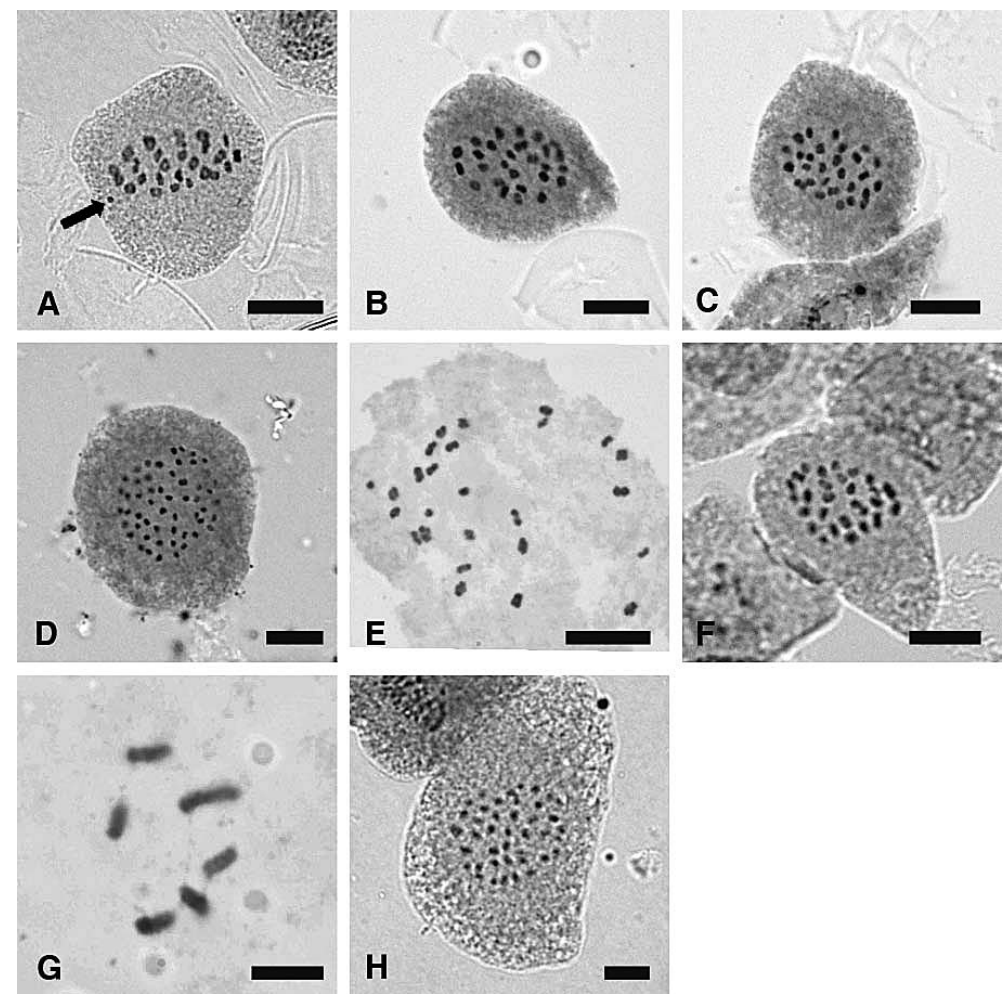

Fig. 1. Photomicrographs of Carex meiotic metaphase chromosomes. A. C. ischnostachya var. fastigiata (n=26II+I, Chung et al. 14), the arrow indicates a univalent. B. C. leucochlora ( $n=27 \mathrm{II}$, Chung et al. 30); C. C. leucochlora ( $n=29 \mathrm{II}$, Chung et al. s.n.). D. C. neurocarpa (n=54II, Chung et al. s.n.). E. C. polyschoena (n=26I, Hoshino et al. s.n.). F. C. sabynensis ( $n=27 \mathrm{II}$, Yang et al. s.n.). G. C. siderosticta ( $n=6$, Hoshino et al. s.n.). H. C. tristachya ( $n=21 \mathrm{II}$, Chung et al. 10). Scale bar $=5 \mu \mathrm{m}$.

Table 1. Species, localities, voucher specimens, and chromosome numbers of Carex collected from Korea.

\begin{tabular}{|c|c|c|}
\hline Specie, locality, and voucher information & $\begin{array}{l}\text { Chromosome } \\
\text { number counted } \\
\text { in this study }(2 n)\end{array}$ & Previous report (2n) \\
\hline $\begin{array}{l}\text { Carex ischnostachya Steud. var. fastigiata T. Koyama } \\
\text { Mt. Ilseongsan, Hwawon-myeon, Haenam-gun, Jellanam-do, South Korea } \\
\text { (Chung et al. 14, April } 28 \text { 2012, KH) }\end{array}$ & $53(n=26 \mathrm{II}+\mathrm{I})$ & 62 (Ohkawa and Yokota 1998) \\
\hline C. leucochlora Bunge & $54(n=27 \mathrm{II})$ & 64, 68 (Tanaka 1939) \\
\hline $\begin{array}{l}\text { Mt. Jujaksan, Bugil-myeon, Haenam-gun, Jeollanam-do, South Korea } \\
\text { (Chung et al. 30, April } 28 \text { 2012, KH) }\end{array}$ & $58(n=29 I \mathrm{II})$ & $\begin{array}{l}72 \text { (Okuno 1939) } \\
68 \text { (Hoshino 1981, Ohkawa and Yokota 1998) }\end{array}$ \\
\hline $\begin{array}{l}\text { C. neurocarpa Maxim. } \\
\text { Mochung-dong, Seowongu, Cheongju-si, Chungcheongbuk-do, South Korea } \\
\text { (Chung et al. s.n., May } 11 \text { 2011, KH) }\end{array}$ & $108(n=54 \mathrm{II})$ & 108 (Tanaka 1937) \\
\hline $\begin{array}{l}\text { C. polyschoena H. Lév. \& Vaniot } \\
\text { Korea National Arboretum, Socheur-eup, Pocheon-si, Gyeonggi-do, South } \\
\text { Korea N 37.73919, E } 127.17045 \text { (Hoshino } \text { et al. s.n. Mar. } 15 \text { 2015, KH) }\end{array}$ & $52(n=26 \mathrm{II})$ & \\
\hline $\begin{array}{l}\text { C. sabynensis Less. ex Kunth } \\
\text { Korea National Arboretum, Socheur-eup, Pocheon-si, Gyeonggi-do, South } \\
\text { Korea (Yang et al. s.n., April } 12 \text { 2012, KH) }\end{array}$ & $54(n=27 \mathrm{II})$ & $\begin{array}{l}40 \text { (Krogulevich 1971) } \\
60 \text { (Yurtsev and Zhukova 1982) }\end{array}$ \\
\hline $\begin{array}{l}\text { C. siderosticta Hance } \\
\text { Korea National Arboretum, Socheur-eup, Pocheon-si, Gyeonggi-do, South } \\
\text { Korea N 37.74615, E } 127.17094 \text { (Hoshino et al. s.n. Mar. } 15 \text { 2015, KH) }\end{array}$ & $12(n=6 \mathrm{II})$ & $\begin{array}{l}\text { 12, } 24 \text { (Hoshino and Tanaka 1977, Hoshino 1981) } \\
12 \text { (Chung et al. 2013) } \\
24 \text { (Tang and Xiang 1989, Starodubtsev 1989, Hoshino } \\
\quad \text { et al. 1993, Probatova et al. 1998, Probatova 2000) }\end{array}$ \\
\hline $\begin{array}{l}\text { C. tristachya Thunb. } \\
\text { Mt. Ilseongsan, Hwawon-myeon, Haenam-gun, Jellanam-do, South Korea } \\
\text { (Chung et al. 10, April } 28 \text { 2012, KH), Seosan-si, Chungcheongnam-do, } \\
\text { South Korea (Yang et al. s.n. Feb. } 9 \text { 2015, KH) }\end{array}$ & $42(n=21 \mathrm{II})$ & $40,41,64$ (Tanaka 1948) \\
\hline
\end{tabular}

propionic acid $(6: 3: 2)$. Fixed anthers were squashed in $2 \%$ acetic-orcein and observed at $1000 \times$ magnification and photographed. At least three meristematic cells per sample were analyzed to determine meiotic chromosome numbers. All voucher specimens are housed at the Korea National Arboretum Herbarium (KH) (Table 1). 
Results and discussion

Meiotic chromosome numbers are summarized with previous records in Table 1. Bivalents and a univalent are observed. None of the species exhibit distinct primary constriction, and all chromosomes are less than $1 \mu \mathrm{m}$ long except for Carex siderosticta (Fig. 1).

Carex ischnostachya Steud. var. fastigiata T. Koyama $(n=26 \mathrm{II}+\mathrm{I}$, Fig. 1A) - Sect. Ischnostachyae

The chromosome number for $C$. ischnostachya var. fastigiata from a Korean population is $n=26 \mathrm{II}+\mathrm{I}$, which is a new number for the taxa. The observation of a univalent is common in Carex due to holocentric chromosome structures (Hoshino 1981, Luceño and Guerra 1996, Chung et al. 2011). This number differs from previous reported somatic chromosome number $2 n=62$ collected from Japan (Ohkawa and Yokota 1998, Hoshino et al. 2011). Hoshino (1981) confirmed the somatic chromosome number of $C$. ischnostachya var. ischnostachya $2 n=62$, which was collected from Hiroshima, Japan. Our new number for the taxon is the first report from meiotic chromosomes of a Korean population. The species occurs only in Korea and Japan, and chromosome numbers from the two geographical regions are incongruent. The chromosome number variations among populations require further investigation with geographic and morphological features together.

C. leucochlora Bunge ( $n=27 \mathrm{II}, 29 \mathrm{II}$, Fig. 1B, C)-Sect. Mitratae

In an individual of $C$. leucochlora, two meiotic chromosome numbers $n$ 27=II, 29II are observed, which is the first count from a Korean population. Previous chromosome counts for the species vary from $2 n=64$ to $2 n=72$ (Table 1, Tanaka 1939, Okuno 1939, Hoshino 1981, Ohkawa and Yokota 1998). C. leucochlora is widely distributed in East Asia including Korea, Japan, northeast China, Taiwan, and the Himalayas (Hoshino et al. 2011). Various chromosome numbers for the species might be related to broad geographic distribution and recent speciation events (Chung et al. 2011). To understand the chromosome variation, taxonomic and phylogenetic studies with cytological research on more population samples should be conducted.

C. neurocarpa Maxim. ( $n=54 \mathrm{II}$; Fig. 1D)-Sect. Phleoideae

The meiotic chromosome of $C$. neurocarpa has $n=54 \mathrm{II}$, which is congruent from the previous reports from Japanese populations (Tanaka 1937). Our count is the first report from Korean populations. C. neurocarpa is widely distributed in East Asia. Further cytological research covering broad distribution areas is required to understand chromosome number variation in the taxon. C. neurocarpa is well distinguished from closely related taxa by leaf-like bracts and winged perigynia (Oh 2007, Dai et al. 2010, Hoshino et al. 2011).

\section{C. polyschoena H. Lév. \& Vaniot $(n=26 \mathrm{II}$, Fig. 1E)- Sect. Mitratae}

The meiotic chromosome number for the species is $n=26 \mathrm{II}$, which is the first count for the taxa. The species occurs in forests of Japan, Korea, and China (Hoshino et al. 2011). In Japan, C. polyschoena is found only in Tsushima Island of Nagasaki Prefecture. However, in Korea, the species occurs throughout the country (Oh 2007, Yang et al. 2015). Dai et al. (2010) treated the species as a variant of $C$. pisiformis Boott. Further taxonomic and phylogentic stuides are needed to clarify conflicting species delimitations and understand species evolution.

C. sabynensis Less. ex Kunth ( $n=27 \mathrm{II}$, Fig. 1F)-Sect. Mitratae

We observed meiotic chromosomes of $n=27$ II from $C$. sabynensis, which is incongruent with previous reports $2 n=60$ (Yurtsev and Zhukova 1982) and 2n=40 (Krogulevich 1971). The species is distributed in broad areas in East Asia, growing in open meadows or wet places in Japan, Korea, eastern Siberia, and northeast China (Hoshino et al. 2011). The broad geographic distribution associated with morphological character variations might result in the incongruent cytological characters.

C. siderosticta Hance ( $n=6$, Fig. 1G) -Sect. Siderostictae

Six chromosomes are observed at pollen mitotic metaphase. Previous counts from Korea are diploids with chromosome numbers of $2 n=12$ (Chung et al. 2013). In China, Japan, and Russia, both diploids, tetraploids, or either have been reported: $2 n=12,24$ from Japan (Hoshino and Tanaka 1977, Hoshino 1981, Hoshino et al. 1993), $2 n=24$ from China and Russia (Tang and Xiang 1989, Starodubtsev 1989, Probatova et al. 1998, Probatoba 2000). Although aneuploidy is known to play an important role in Carex speciation, in Carex sect. Siderostictae, polyploidy is an important speciation mechanism.

C. tristachya Thunb. (n=21II, Fig. 1H) - Sect. Mitratae

The chromosome number counts from two Korean populations are reported as $n=21 \mathrm{II}$, which disagrees with previous reports $(2 n=40,41,64$; Tanaka 1948). The species is found on the sunny sides of grassland and forest edges in Korea, Japan, and China (Dai et al. 2010). Although it is common to have chromosome number variation within a species, among populations, and even in individuals in Carex (Roalson 2008, Hipp et al. 2011, Chung et al. 2011), taxonomic research on the species is desired to resolve obscure species delimitation by studies on morphological variation.

The chromosome number $2 n=52$ for $C$. polyschoena 
is first reported in this study. Although this species is common in South Korea, it is designated as Endangered II in Japan, and found only on Tsushima Island. C. polyschoena is very close to C. stenostachya Franch. \& Sav., which is common in western Japan. A continuous aneuploid series, $2 n=58,59,60$, and 61, is reported (Hoshino et al. 1993). Further cytological studies are needed to elucidate the chromosomal differentiation in South Korean and Japanese populations. Although only diploid chromosome numbers are found in C. siderosticta from South Korean populations, tetraploids are common in Chinese and Japanese populations. Additional cytological data from South Korea, which is located between China and Japan, is needed. More cytological studies are also needed in order to explain the mechanisms of the aneuploidal diversification of four species, C. ischnostachya var. fastigiata, C. leucochlora, C. sabynensis, and $C$. tristachya, for which different chromosome numbers from previous reports are found.

\section{Acknowledgements}

This study was conducted as a part of the "Cytological study of Cyperaceae in Korea" project funded by the Korea National Arboretum.

\section{References}

Chung, K.-S., Hipp, A. L. and Roalson, E. H. 2012. Chromosome number evolves independently of genome size in a clade with non-localized centromeres (Carex: Cyperaceae). Evolution 69: 2708-2722.

Chung, K.-S., Weber, J. A. and Hipp, A. L. 2011. The dynamics of chromosome and genome size variation in a cytogenetically variable sedge (Carex scoparia var. scoparia, Cyperaceae). Am. J. Bot. 98: 122-129.

Chung, K.-S., Yang, J. C. and Lee, Y.-M. 2013. Chromosome numbers of Carex section Siderostictae from Korea populations (Cyperaceae). Korean J. Plant Taxonomy 43: 1-5.

Dai, L., Liang, S., Zhang, S., Tang, Y., Koyama, T. and Tucker, G. C. 2010. Carex Linneaus. In: Zhengyi, W., Raven, P. H. and Deyuan, H. (eds.). Flora of China: Acoraceae through Cyperaceae. Missouri Botanical Garden Press, St. Louis. pp. 285-461.

Davies, E. W. 1956. Cytology, evolution and origin of the aneuploid series in the genus Carex. Hereditas 42: 349-365.

Escudero, M., Hipp, A. L., Waterway, M. J. and Valente, L. M. 2012. Diversification rates and chromosome evolution in the most diverse angiosperm genus of the temperate zone (Carex, Cyperaceae). Mol. Phylogenet. Evol. 63: 650-655.

The Global Carex Group 2015. Making Carex monophyletic (Cyperaceae, tribe Careiceae): A new broader circumscription. Bot. J. Linn. Soc. 179: 1-42.

Hipp, A. L. 2007. Non-uniform processes of chromosome evolution in sedges (Carex: Cyperaceae). Evolution 61: 2175-2194.

Hipp, A. L., Escudero, M. and Chung, K.-S. 2013. Holocentric Chromosomes. In: Maloy, S. and Hughes, K. (eds.). Encyclopedia of Genetics, 2nd Edition. Vol. 3. Elsevier, New York. pp. 499-501.

Hipp, A. L., Rothrock, P. E. and Roalson, E. H. 2009. The evolution of chromosome arrangements in Carex (Cyperaceae). Bot. Rev. 75: $96-109$.

Hipp, A. L., Rothrock, P. E., Whitkus, R. and Weber, J. A. 2010.
Chromosomes tell half of the story: The correlation between karyotype rearrangements and genetic diversity in sedges, a group with holocentric chromosomes. Mol. Ecol. 19: 3124-3138.

Hoshino, T. 1981. Karyomorphological and cytogenetical studies on aneuploidy in Carex. J. Sci. Hiroshima Univ. Div. 2, Ser. B 17 : $155-238$.

Hoshino, T., Okamura, K., Hong, D. Y., Dai, L. K., Nakata, M. and Tanaka, R. 1993. Cytological studies of Chinese Cyperaceae (1). Chromosome counts of nine species collected from Jilin, Liaoning and Hebei provinces. J. Jpn. Bot. 68: 65-69.

Hoshino, T. and Tanaka, R. 1977. Karyomorphological studies of Carex siderosticta and its two allied species. Kromosomo II 7-8: 191-194.

Hoshino, T., Aosaki, K. and Onimatsu, A. 1993. Cytological studies of Carex stenostachys (Cyperaceae) with special references to meiotic configurations of intraspecific aneuploids. La Kromosoma II. 71-72: 2451-2455.

Hoshino, T., Masaki, T. and Nishimoto, M. 2011. Illustrated Sedges of Japan. Heibonsha Ltd., Tokyo.

Kim, K. J., Kim, Y.-D., Kim, J.-H., Park, S.-J., Park, C.-W., Sun, B.-Y., Yoo, K.-O., Choi, B.-H. and Kim, S. T. 2008. Phlyogenetic classification of Korean vascular flora according to the recent APG classification system. Korean J. Pl. Taxon 38: 197-222.

Kim, S. Y. 2006. Establishment of Chromosome D/B and Molecular Cytogenetic Analysis of Korean Native Plants. [Doctoral Disseration]. [Chungnam]: Chungnam National University.

Krogulevich, R. E. 1971. The Role of Polyploidy in the Genesis of the Alpine Flora of the Stanovoye Nagorye Mountains. In: The Ecology of the Flora of the Trans-Baikal region. Vol. 115. Chungnam National Univ. Irkutsk. pp. 115-214.

Lee, J. and Kim, S. Y. 2008. Chromosomes of Endemic Plants in Korea 2008. Korea Research Institute of Bioscience and Biotechnology, Daejeon.

Luceño, M. and Guerra, M. 1996. Numerical variations in species exhibiting holocentric chromosomes: A nomenclatural proposal. III-IV. Caryologia 49: 301-309.

Nishikawa, K., Furuta, Y. and Ishitoba, K. 1984. Chromosomal evolution in genus Carex as viewed from nuclear DNA content, with special reference to its aneuploidy. Jpn. J. Hum. Genet. 59: $465-472$.

Oh, Y. C. 2007. Cyperaceae juss. In: Flora of Korea Editorial Committee (ed.), The Genera of Vascular Plants of Korea. Academy Publishing Co., Seoul. pp. 1113-1181.

Ohkawa, T. and Yokota, M. 1998. Chromosome numbers and their variation patterns of Carex in the Ryukyu Islands. Cytologia 63: 415-420.

Okuno, S. 1939. Chromosome numbers in the genus Carex. Jpn. J. Genet. 15: 332-333.

Probatova, N. S. 2000. Chromosome numbers in some plant species from the Razdolnaya (Suifun) river basin (Primorsky Territory). Bot. Žhurn. (Moscow \& Leningrad) 85: 102-107.

Probatova, N. S., Rudyka, E. G. and Sokolovskaya, S. A. 1998. Chromosome umbers in vascular plants from the islands of Peter the Great Bay and Muravyov-Amurskiy Peninsula (Primorsky territory). Bot. Žhurn. (Moscow \& Leningrad) 83: 125-130.

Reznicek, A. A. 1990. Evolution in sedges (Carex, Cyperaceae). Can. J. Bot. 68: 1409-1432.

Roalson, E. H. 2008. A synopsis of chromosome number variation in the Cyperaceae. Bot. Rev. 74: 209-393.

Rothrock, P. E. and Reznicek, A. A. 1996. Chromosome numbers in Carex section Ovales (Cyperaceae) from Eastern North America. Sida 17: 251-258.

Rothrock, P. E., Reznicek, A. A. and Hipp, A. L. 2009. Taxonomic study of the Carex tenera group (Cyperaceae). Syst. Biol. 34: 297-311.

Starodubtsev, V. N. 1989. Chromosome numbers in species of the 
families Aceraceae, Brassicaceae, Cyperaceae, Euphorbiaceae, Papaveraceae and Ranunculaceae from the Soviet fareast. Bot. Žhurn. (Moscow \& Leningrad) 74: 1674-1675.

Tanaka, N. 1937. Chromosome studies in Cyperaceae I. Cytologia Fugii Jub.: 814-821.

Tanaka, N. 1939. Chromosome studies in Cyperaceae IV. Chromosome number of Carex species. Cytologia 10: 51-58.

Tanaka, N. 1948. The problem of anueploidy (Chromosome studies in Cyperaceae, with special reference to the problem of anueploidy). Biol. Contr. Japan 4: 1-327.

Tanaka, N. 1949. Chromosome studies in the genus Carex with special reference to aneuploidy and polyploidy. Cytologia 15: 15-29.
Tang, Y. C. and Xiang, G. Y. 1989. A cytological study of Carex siderosticta Hance (Cyperaceae) and its implication in phytogeography. Cathaya 1: 49-60.

Yang, J. C., Shin, C. H., Choi, K., Jang, K. S. and Ji, S. J. 2015. Field Guide to the Sedges 100 of Korea. GeoBook, Seoul.

Yano, O., Ito, K., Katsuyama, T., Ikeda, H. and Hoshino, T. 2010. Cytological study of Carex omurae and C. phaeodon (Cyperaceae). J. Jpn. Bot. 85: 370-372.

Yurtsev, B. A. and Zhukova, P. G. 1982. Chromosome numbers of some plants of the northeastern Yakutia (the drainage of the Indigirka River in its middle reaches). Bot. Zhurn. 67: 778-787. 